\title{
Smoking onset and the time-varying effects of self-efficacy, environmental smoking, and smoking-specific parenting by using discrete-time survival analysis
}

\author{
Marieke Hiemstra • Roy Otten • \\ Rutger C. M. E. Engels
}

Received: October 15, 2010 / Accepted: May 18, 2011 /Published online: June 4, 2011

(C) The Author(s) 2011. This article is published with open access at Springerlink.com

\begin{abstract}
This study examined the timing of smoking onset during mid- or late adolescence and the time-varying effects of refusal self-efficacy, parental and sibling smoking behavior, smoking behavior of friends and best friend, and parental smoking-specific communication. We used data from five annual waves of the 'Family and Health' project. In total, 428 adolescents and their parents participated at baseline. Only never smokers were included at baseline $(n=272)$. A life table and Kaplan-Meier survival curve showed that $51 \%$ of all adolescents who did not smoke at baseline did not start smoking within 4 years. The risk for smoking onset during mid- or late adolescence is rather stable (hazard ratio between 16 and 19). Discretetime survival analyses revealed that low refusal self-efficacy, high frequency of communication, and sibling smoking were associated with smoking onset one year later. No interaction effects were found. Conclusively, the findings revealed that refusal self-efficacy is an important predictor of smoking onset during mid- or late adolescence and is independent of smoking-specific communication and smoking behavior of parents, siblings, and (best) friend(s). Findings emphasize the importance of family prevention programs focusing on self-efficacy skills.
\end{abstract}

Keywords Smoking onset - Refusal self-efficacy · Smoking-specific parenting $\cdot$ Adolescence $\cdot$ Friends . Discrete-time survival analysis

M. Hiemstra $(\bowtie) \cdot$ R. Otten · R. C. M. E. Engels

Behavioural Science Institute, Radboud University Nijmegen,

P.O. Box 9104, 6500 HE Nijmegen, The Netherlands

e-mail: m.hiemstra@bsi.ru.nl

\section{Introduction}

In most Western countries, smoking onset increases most rapidly during adolescence. In $2009,7 \%$ of 11 -years-old adolescents in the Netherlands indicated that they had tried smoking during their lifetime. This increased to $45 \%$ by the age of 14 and $62 \%$ by age 17 (Stivoro, 2009). These smoking rates are similar to those in the UK (National Centre for Social Research, 2010) and the US ((MMWR) 2010). It is important to prevent young adolescents from smoking because people who initiate smoking early in life are more likely to develop a long-enduring smoking habit (e.g., Chassin et al., 2000). To better prevent the onset of adolescent smoking, increased insight into the exact timing of adolescent smoking and its predictors is necessary. The aim of the present study was to gain insight into the timing of smoking onset and the time-varying effects of refusal self-efficacy, environmental smoking, and smoking-specific parenting throughout mid- or late adolescence.

One way to look at the timing of smoking onset is by means of survival analyses (Willet \& Singer, 1991; Willet \& Singer, 1993), also called event history analyses (Allison, 1984). Survival analyses encompass a wide variety of statistical methods to analyze occurrence and timing of events, and it offers two main advantages in comparison to traditional analytic methods to examine behavior over time (Willet \& Singer, 1993). Particularly, when studying adolescent smoking, most traditional studies aimed at smoking onset ignore the time to when smoking occurs, and do not take into account the censoring of smoking behaviors (Bidstrup et al., 2009; Grogan et al., 2009; Lotrean et al., 2010). Censoring is an important feature of survival-time data. Specifically, the survival times of some respondents are unobserved, for instance, because smoking onset did not take place before the termination of the study, which 
makes information about the occurrence of smoking onset of these respondents (i.e., respondents with censored data) incomplete. Failure to take this specific feature of survival data into account can produce serious bias in estimates of the distribution of survival time and related quantities. Standard statistical tools do not allow the calculation of the mean duration of episodes when observations are censored (Systema et al., 1996).

The present study used discrete-time survival analyses (Singer \& Willet, 1993; Willet \& Singer, 1993) because data were gathered at specific time points and not continuously over time. Discrete-time survival analysis allows for examination of the longitudinal progression of the probability that an event occurs (Muthen \& Masyn, 2005); thereby, providing a more accurate insight into whether adolescents start smoking and when (Singer \& Willet, 1993; Willet \& Singer, 1991; Willet \& Singer, 1993). Furthermore, the majority of longitudinal studies measure predictors at one point in time thereby partially overlooking the idea that values of predictors may vary over time, and not permitting the effects of the predictors to fluctuate (Willet \& Singer, 1991). Discrete-time survival analysis allows the inclusion of time varying predictors, whose values fluctuate over time. In conclusion, by means of survival analyses a more accurate prediction of smoking onset can be made. As an additional consequence, the use of survival analyses may cause magnitudes of effects to differentiate (i.e. be weaker or stronger in magnitude) from those found in studies using more traditional techniques.

One important predictor that is assumed to vary over time and affects adolescent smoking is refusal self-efficacy (de Vries et al., 1988; Engels et al., 1997), which refers to adolescents' confidence in their ability to stay a non-smoker and the confidence to refuse a cigarette (de Vries et al., 1988; Engels et al., 1999). Self-efficacy has been widely used to explain smoking initiation in youths (e.g., Petraitis et al., 1995). In some longitudinal studies, higher levels of selfefficacy related negatively to smoking onset (e.g., Bidstrup et al., 2009; Chang et al., 2006; de Vries et al., 1995; Grogan et al., 2009; Lotrean et al., 2010) but in other studies, selfefficacy did not relate to adolescent smoking onset (e.g., Ayo-Yusuf et al., 2009). Despite the prospective nature of these studies, only some of these studies took smoking onset at different time points into account (Bidstrup et al., 2009; Chang et al., 2006; Lotrean et al., 2010). Most studies assessed self-efficacy and smoking initiation over a short period (two or three time points) (Bidstrup et al., 2009; Chang et al., 2006; Grogan et al., 2009; Lotrean et al., 2010). Moreover, some of these studies applied relatively small time intervals (2-year or shorter), limiting the possibility to examine the smoking onset throughout adolescence (Bidstrup et al., 2009; de Vries et al., 1995; Grogan et al., 2009; Lotrean et al., 2010).
Besides self-efficacy, parental, sibling, and peer smoking are associated with adolescent smoking (e.g., Avenevoli \& Merikangas, 2003; Harakeh et al., 2007; Otten et al., 2009). Parental smoking status affects the likelihood that adolescents will start smoking and, over time, the development of a more habitual smoking pattern (e.g., Mayhew et al., 2000; Gilman et al., 2009). Smoking behavior of an older sibling affects smoking onset of an adolescent (Avenevoli \& Merikangas, 2003; Harakeh et al., 2007), although friends' smoking is considered to be a stronger predictor of adolescent smoking than sibling smoking (Avenevoli \& Merikangas, 2003). Adolescents with smoking friends have been found to be more likely to smoke themselves as compared to adolescents with nonsmoking friends (for a review see Hoffman et al., 2006; Kobus 2003).

Another parental factor, smoking-specific parenting, has been shown to be important in adolescent smoking behavior (Chassin et al., 1998; Conrad et al., 1992). Smoking-specific parenting includes specific strategies aimed at preventing smoking onset by setting rules, transmitting knowledge on smoking, and encouraging antismoking attitudes (i.e., antismoking socialization) (e.g., Engels \& Willemsen, 2004; Ennett et al., 2001; Harakeh et al., 2005; Jackson \& Dickinson, 2003). Earlier research established that smoking-specific parenting practices reduce the odds of adolescents being involved in smoking (e.g., Chassin et al., 2005; de Leeuw et al., 2008; de Leeuw et al., 2010; Harakeh et al., 2005). Moreover, parents engage in different socializing efforts, such as constructive forms of communication about smoking issues, to influence their adolescent's decision to smoke. Previous research has found that frequency of communication is associated with adolescent smoking (e.g., positively: Chassin et al., 1998; Clark et al., 1999; Jackson \& Henriksen, 1997; negatively: Ennett et al., 2001; Harakeh et al., 2005). Higher quality of communication was negatively associated with adolescent smoking (e.g., Chassin et al., 2005; de Leeuw et al., 2008; de Leeuw et al., 2010; Harakeh et al., 2005; Otten et al., 2007). The divergent findings with respect to frequency and quality of communication could be a reflection of parents' reaction to the smoking behavior of the adolescent.

Self-efficacy, environmental smoking, and smokingspecific communication are included in some of the most important theories in explaining adolescent health risk behavior (Petraitis et al., 1995). These theories have suggested that the major influences on adolescent smoking are social environments and psychological factors. Specifically, environmental smoking has been found to affect adolescent smoking through processes of modeling (e.g., Engels et al., 1999), accordingly with social cognitive theories (Bandura, 1986), and parents exert socializing efforts through constructive forms of communication (Otten et al., 2007). From 
a similar theoretical perspective, yet on a more individual level, refusal self-efficacy has been shown to protect children from smoking (e.g., Petraitis et al., 1995). In addition to the direct effects of self-efficacy, environmental smoking exposure, and smoking-specific parenting on smoking onset, it is likely that smoking behavior is a product of an interplay between individual and environmental factors. Specifically, we expect a weaker role of self-efficacy in children exposed to both peers and parent who smoke (e.g., Bauman et al., 2001; de Vries et al., 2003). Environmental smoking and communication about of smoking may affect refusal selfefficacy in a respectively negative and positive way, which in turn may decrease or increase the odds for adolescent smoking. Adolescents of parents who smoke may perceive smoking as relatively normative behavior (Bricker et al., 2007). As a consequence, these children may be less likely to refuse a cigarette. We also expect a stronger role of selfefficacy in children whose parents engage in smoking-specific parenting (Engels \& Willemsen, 2004; Huver et al., 2006; Otten et al., 2007). Parents play an important role in encouraging a child's self-efficacy: children of parents who discuss smoking matters are expected to be more confident in their ability to refuse cigarettes from peers.

The present study

The main objective of the present study was to examine the timing of smoking onset during mid- or late adolescence and the time-varying effects of refusal self-efficacy, parental smoking, sibling smoking, friends and best friend's smoking, and smoking-specific communication. In addition, we examined how the exposure to environmental smoking (i.e., parental, sibling, and peer smoking) and smoking-specific parenting (i.e., frequency and quality of communication) might alter the relation between self-efficacy and adolescent smoking onset during mid- or late adolescence. This was tested using survival analyses. We expected that lower selfefficacy, smoking behavior of parents, older sibling, peers, and more frequent communication as well as lower quality of communication would be important predictors of the timing of smoking onset. Further, we expected that environmental smoking and smoking-specific communication alter the relationship between self-efficacy and smoking onset.

\section{Methods}

\section{Procedure}

Data were used from five annual waves of a longitudinal Dutch study 'Family and Health,' which focused on factors underlying various health behaviors in adolescence (e.g., Harakeh et al., 2005) and to investigate the influences from father, mother, and sibling simultaneously. We selected 5,062 addresses of families consisting of father, mother, and two adolescents aged 13-16 years from 22 municipality registers. A letter was sent to all these families, inviting them to participate in this study. In total, 885 families responded. From these families, 765 met the inclusion criteria (i.e., parents were married or were living together and all family members had to be biologically related). Because of financial resources, we were restricted to include 428 families in the project. A further selection was made to achieve an equal division of education and an equal amount of sibling dyads (i.e., 108 boy-boy, 118 boy-girl, 106 girl-girl, and 96 girl-boy).

Between November 2002 and April 2003 (T1), an interviewer visited the families in their homes. During the home visit, each family member was asked to complete a questionnaire individually. To maintain anonymity, respondents were asked to sit apart from each other and not to discuss the questions with each other. The numbers of participating families at follow-up were 416 (T2), 404 (T3), 356 (T4), and 326 (T5), which is a 76\% response rate across the five waves. Each family received $€ 30$ per wave if all four family members completed the questionnaires.

Sample characteristics

At T1, we selected only the youngest non-smoking adolescents $(n=272)$, which allowed us to examine smoking onset over the course of adolescence. Of the initial sample $(N=428), \quad 272(63.6 \%)$ adolescents reported never smoking at T1. Boys and girls were approximately equally represented, with $52 \%$ of the adolescents being girls. The age of adolescents ranged from 13 to 15 years, with a mean age of 13.3 years $(S D=0.48)$, and the majority was Dutch $(95.2 \%)$. Education level was equally represented. Table 1 describes the characteristics of the initiators and nonsmokers at baseline. Early initiators showed lower levels of self-efficacy, reported higher levels of environmental smoking, lower frequency of communication and higher quality of communication.

Attrition analyses revealed differences between adolescents who participated in the study at all time points and those who dropped out. Adolescents that dropped out were less likely to follow higher education $(O R=.89,95 \% C I=$ $.62-1.26, P<.01)$ and were more likely to have smoking friends $(O R=1.69,95 \% C I=1.04-2.75, P<.05)$.

\section{Measures}

\section{Adolescent smoking}

Smoking behavior of the adolescent was assessed five times with one-year intervals using a well-established measure (de Vries et al., 2003; Kremers et al., 2001). 
Table 1 Descriptive statistics for the smoking behavior of adolescent, peers, sibling, and parents, refusal self-efficacy, and smoking-specific parenting variables at $\mathrm{T} 1-\mathrm{T} 5$

\begin{tabular}{|c|c|c|c|c|c|c|c|}
\hline \multirow[t]{2}{*}{ Variable } & \multirow{2}{*}{$\begin{array}{l}\text { Smokers } \\
(n=153)^{\mathrm{a}} \\
\mathrm{T} 1 \\
\mathrm{M}(\mathrm{SD})\end{array}$} & \multicolumn{6}{|c|}{ Non-smokers $(n=272)^{\mathrm{a}}$} \\
\hline & & $\begin{array}{l}\mathrm{T} 1 \\
\mathrm{M}(\mathrm{SD})\end{array}$ & $\begin{array}{l}\mathrm{T} 2 \\
\mathrm{M}(\mathrm{SD})\end{array}$ & $\begin{array}{l}\text { T3 } \\
\text { M (SD) }\end{array}$ & $\begin{array}{l}\mathrm{T} 4 \\
\mathrm{M}(\mathrm{SD})\end{array}$ & $\begin{array}{l}\text { T5 } \\
\text { M (SD) }\end{array}$ & Range \\
\hline \multicolumn{8}{|l|}{ Mother } \\
\hline Adolescent smoking & $3.33(2.40)^{* * *}$ & $1.00(.00)$ & $1.45(1.40)$ & 1.79 (1.94) & $2.18(2.35)$ & $2.32(2.47)$ & $1-9$ \\
\hline Refusal self-efficacy & $4.55(1.06)$ & $5.05(.87)^{* * *}$ & $5.11(.89)$ & $5.10(.96)$ & $5.18(1.01)$ & $5.21(1.01)$ & $1-6$ \\
\hline Friends & $2.11(1.00)^{* * *}$ & $1.43(.63)$ & $1.68(.80)$ & $1.98(.95)$ & $2.11(.92)$ & $2.24(.98)$ & $1-5$ \\
\hline Best friends & $3.01(2.80)^{* * *}$ & $1.49(1.23)$ & $1.83(1.82)$ & $2.32(2.38)$ & $2.75(2.62)$ & $3.12(2.80)$ & $1-9$ \\
\hline Sibling smoking & $3.29(2.78) * * *$ & $2.02(2.07)$ & $2.31(2.35)$ & $2.65(2.65)$ & $2.97(2.80)$ & $3.14(2.94)$ & $1-9$ \\
\hline Parental smoking & $3.05(1.28)^{*}$ & $2.62(1.30)$ & $2.51(1.23)$ & $2.49(1.24)$ & $2.50(1.23)$ & $2.42(1.15)$ & $1-5$ \\
\hline Frequency of communication & $2.08(.87)^{*}$ & $1.89(.64)$ & $1.77(.65)$ & $1.72(.62)$ & $1.60(.58)$ & $1.54(.52)$ & $1-5$ \\
\hline Quality of communication & $3.33(.62)$ & $3.67(.57)^{* * *}$ & $3.58(.66)$ & $3.56(.67)$ & $3.63(.66)$ & $3.67(.73)$ & $1-5$ \\
\hline \multicolumn{8}{|l|}{ Father } \\
\hline Parental smoking & $2.99(1.31)$ & $2.64(1.31)$ & $2.60(1.28)$ & $2.51(1.22)$ & $2.55(1.27)$ & $2.51(1.23)$ & $1-5$ \\
\hline Frequency of communication & $1.98(.90)$ & $1.87(.74)$ & $1.74(.69)$ & $1.68(.70)$ & $1.54(.57)$ & $1.44(.49)$ & $1-5$ \\
\hline Quality of communication & $3.34(.68)$ & $3.67(.62)^{* * *}$ & $3.58(.72)$ & $3.53(.68)$ & $3.51(.72)$ & $3.57(.77)$ & $1-5$ \\
\hline
\end{tabular}

Asterisks indicate significantly higher value for that group (initiators or non-smokers at T1). Chi-square test for categorical variables; t-tests for continuous variables. ${ }^{\mathrm{a}}$ Sample sizes smaller for some items because of missing data. $* * * P<.001$, $* * P<.01, * P<.05$

Adolescents were asked to report, on a nine-point scale, which stage of smoking applied to them. Response categories ranged from 1 (I have never smoked, not even one puff) to 9 (I smoke at least once a day). We recoded these responses as non-smoker $=0$ (never smoking) and smoker $=1$ (any experience with lifetime smoking) (Harakeh et al., 2005).

\section{Refusal self-efficacy}

At each wave, self-efficacy was measured with six items on a six-point-scale ranging from 1 (very difficult) to 6 (very easy), e.g., 'To become (or to stay) a nonsmoker is ....' and 'Not to smoke if my friends are smoking is for me...' (de Vries et al., 1988; de Vries et al., 1995). Cronbach's alphas ranged from .85 to .91 across waves. A higher score on the self-efficacy scale indicated higher efficacy to refuse a cigarette. The scale used in the present study has been used in various health studies in the Netherlands (de Vries et al., 1995; Engels \& Willemsen, 2004; Harakeh et al., 2004; Otten et al., 2007). The psychometric properties of selfefficacy were sufficient to good with high internal consistencies (alpha's $>.85$ ) and support for one underlying factor (de Vries et al., 1988).

\section{Parental smoking}

At each wave, parents were asked to report which stage of smoking applied to them using the same scale as for the adolescents (de Vries et al., 2003). However, one of the nine responses was less appropriate for adults (i.e., 'I tried smoking once in a while'); therefore, parents responded on an eight-point scale (cf., Harakeh et al., 2005). Because of the skewness of the distribution over the eight categories and to establish a more robust measure of parental smoking, this variable was transformed to a new variable ranging from 1 to 5 ( $1=$ 'I have never smoked, not even one puff'; 2 = 'I tried smoking, I don't smoke anymore'; $3=$ 'I stopped smoking, after smoking at least once a month' (based on the initial responses 'I stopped smoking, after smoking less than once a week' and 'I stopped smoking, after smoking at least once a week'); $4=$ 'I smoke occasionally, but not every day' (based on 'I smoke less than once a month', and 'I smoke not weekly, but at least once a month', and 'I smoke not daily, but at least once a week'); 5 = 'I smoke at least once a day') (cf. Otten et al., 2007).

\section{Sibling smoking}

At each wave, older siblings were asked the same question about smoking status as the target adolescents (Harakeh et al., 2005).

\section{Friends' smoking}

The proportion of smoking friends was assessed at each wave using the following question: 'How many of your friends smoke?' Responses ranged from 1 (none of my 
friends smoke) to 5 (all my friends smoke) (Engels et al., 1997).

\section{Best friends' smoking}

At each wave, the adolescents were asked to report on a 9-point scale ranging from 1 (My best friend never smoked, not even one puff) to 9 (My best friend smokes at least once a day), which stage of smoking applied to their best friend. Adolescents are rather accurate in estimating their best friends' smoking behavior (Harakeh et al., 2007).

\section{Quality of smoking-specific communication}

Quality of communication was assessed at each wave with six items (per parent). The items on this scale reflect a constructive and respectful way of communicating about smoking-related issues (e.g., 'My mother/father and I are able to talk easily about our opinions concerning smoking'). Adolescents were asked to report on a 5-point scale ranging from 1 (completely not true) to 5 (completely true), which answer applied to them (Harakeh et al., 2005). The scale scores were averaged. Cronbach's alphas across waves ranged from .74 to .86 for adolescents reporting about their mother and from .80 to .88 for adolescents reporting about their father.

\section{Frequency of smoking-specific communication}

Frequency of communication was assessed at each wave by averaging the scores of eight items assessing how often in the past 12 months parents talked with their child about smoking related issues (e.g., 'During the last 12 months, how many times did your mother/father talk to you about how to resist peer pressure to use tobacco?') on a 5-point scale ranging from 1 (never) to 5 (very often) (Ennett et al., 2001; see for an adapted Dutch version: Harakeh et al., 2005). Cronbach's alphas ranged from .87 to .89 (adolescents reporting about their mother) and from .89 to .91 (adolescents reporting about their father) across waves.

\section{Statistical analyses}

For the purpose of this study, at baseline, we included only adolescents who never smoked $(n=272)$. After calculating descriptive statistics, we used survival analyses designed to account for censoring and consider whether and when an event occurs (Willet \& Singer, 1993).

We used the life table to describe the event occurrence data. The life-table is a tool for summarizing the sample distribution of event occurrence (Singer \& Willet, 2003). It tracks the event histories of a sample of respondents from the beginning of through the end of data collection
(4 years). As a statistical summary of the life-table, the Kaplan-Meier survival curve (Kaplan \& Meier, 1958) shows the survivor function. A survival function shows the proportion of respondents who have not experienced the event over time. The life-table approach is useful for the preliminary analysis of survival data; however, this method does not control for the effects of other predictors as do regression models (Allison, 1995).

Therefore, discrete-time survival analyses were used to assess the strength of the association between adolescent smoking onset and other variables. Discrete-time survival analysis treats time not as a continuous variable but as a variable that is divided into certain intervals of time, e.g., once per year (Singer \& Willet, 1993; Willet \& Singer, 1993). The analyses were conducted with logistic regression analyses in SPSS 15.0. To use logistic regression analyses, the dataset needed to be rearranged from a oneperson, one-record data set (272 person-level dataset) to one-person, multiple-period data set $(1,137$ person-period data set). This means that for every respondent in the dataset, we recorded separate lines until the event occurred, with a maximum of five lines (i.e., waves) per respondent.

The following steps were conducted in logistic regression analyses. In the first step, we tested whether the covariates of age, gender, education, and ethnicity related to smoking status. In the second step, self-efficacy, quality of communication, frequency of communication, parental smoking, sibling smoking, and overall friends and best friend smoking of the wave before (T-1) were added. In the third step, interaction terms (T-1) between self-efficacy and the following variables: quality and frequency of communication, parental smoking, sibling smoking, friends and best friend smoking were entered. All the analyses were conducted separately for mother and father.

Kaplan-Meier survival curves were made for the significant results of discrete-time survival analyses. For those purposes, continuous variables were dichotomized $(0=$ low and $1=$ high $)$. Classification into low or high category was based on the median split.

\section{Results}

Of the 272 adolescents, 120 adolescents reported to have smoked at least once between T2 and T5. Descriptive statistics for other (independent) variables are presented in Table 1.

Life table

A life table examined the sample distribution of event occurrence (Table 2), in our case staying a non-smoker or 
Table 2 Life Table

\begin{tabular}{|c|c|c|c|c|c|c|c|c|c|}
\hline Year & $\begin{array}{l}\text { Interval } \\
\text { time }\end{array}$ & $\begin{array}{l}\text { Number of } \\
\text { entering } \\
\text { interval }\end{array}$ & $\begin{array}{l}\text { Number of } \\
\text { withdrawing during } \\
\text { interval (Censored) }\end{array}$ & $\begin{array}{l}\text { Number } \\
\text { exposed to } \\
\text { risk }\end{array}$ & $\begin{array}{l}\text { Number } \\
\text { of } \\
\text { smokers }\end{array}$ & $\begin{array}{l}\text { Proportion } \\
\text { of smokers }\end{array}$ & $\begin{array}{l}\text { Proportion of non- } \\
\text { smokers at the end of } \\
\text { the year }\end{array}$ & $\begin{array}{l}\text { Cumulative } \\
\text { proportion of } \\
\text { non-smokers }\end{array}$ & $\begin{array}{l}\text { Hazard } \\
\text { ratio } \\
(\mathrm{HR})\end{array}$ \\
\hline 1 & {$[0,1]$} & 272 & 3 & 270.50 & 0 & .00 & 1.00 & 1.00 & .00 \\
\hline 2 & {$[1,2]$} & 269 & 4 & 267.00 & 46 & .17 & .83 & .83 & .19 \\
\hline 3 & {$[2,3]$} & 219 & 25 & 206.50 & 30 & .15 & .85 & .71 & .16 \\
\hline 4 & {$[3,4]$} & 164 & 5 & 161.50 & 25 & .15 & .85 & .60 & .17 \\
\hline 5 & {$[4,5]$} & 134 & 5 & 131.50 & 19 & .14 & .86 & .51 & .16 \\
\hline
\end{tabular}

smoking at least once. The first column of the life table describes the 4 years of measurement and the second column the accompanying interval time. The third column depicts the number of respondents who entered each interval. The group of respondents that entered the interval is called 'the risk set,' that is, those who are eligible to experience the event during the interval. The year 3 risk set ( $n=219)$ can be described as the year 2 risk set $(n=269)$ without the 46 adolescents who started smoking during year 2 and the number of censored cases ( $n=4$, withdrawing during the interval). If a respondent started smoking, or was censored, s/he dropped out of the risk set for all remaining time points. The fourth column displays the number of censored cases at the end of each time interval. There are two types of censoring, that is, some respondents would never experience the target event and others would experience the event but not during the study's data collection. Column 5 shows the amount of respondents who experienced the event (smoking) during each interval, column 6 the proportion of smokers, column 7 the proportion of non-smokers, and column 8 the cumulative proportion of these non-smokers. This proportion represents all non-smoking adolescents at baseline who still did not smoke at the end of each year. Our findings showed that $51 \%$ of all non-smoking respondents at baseline did not smoke after 4 years. The last column shows the hazard ratio $(H R)$. The hazard ratio is the proportion of respondents at each interval who did not smoke, who had the possibility to start smoking in the following time interval, and who did not experience the event during the preceding interval. The greater the hazard ratio, the greater the risk to start smoking. The risk to start smoking is rather stable over the adolescent years (between .16 and .19).

\section{Kaplan-Meier survival curve}

In Fig. 1, the Kaplan-Meier survival curve depicts the development of smoking onset over time. The survival function shows the probability that a respondent will not experience the event ("survives"). The figure depicts each

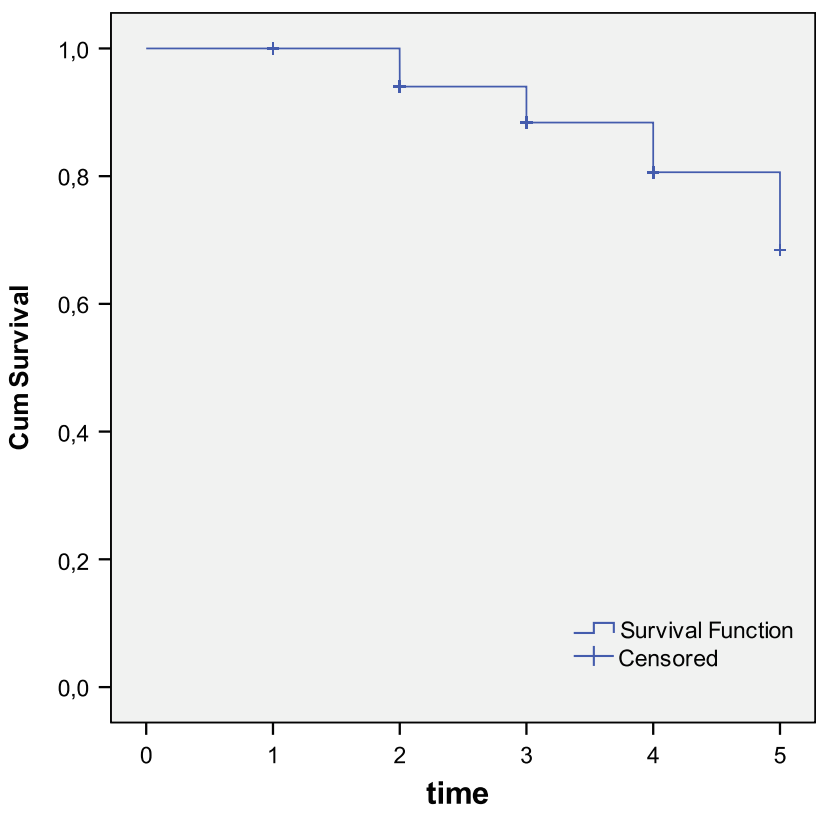

Fig. 1 Kaplan-Meier-survival curve of onset of smoking. Each person who started smoking is showed as a downward step in the curve

person who started smoking as a downward step in the curve. The pattern shows that the number of respondents who start smoking each year is almost stable over time (Fig. 1).

Discrete-time survival analyses

\section{Father}

In the first step, no effects were found for the covariates (Table 3). In step 2, self-efficacy, frequency of communication, and sibling smoking were positively associated with adolescent smoking onset. The effects of friends smoking and best friends smoking were almost significant Adolescents with higher levels of self-efficacy 1 year earlier were at lower risk to start smoking 1 year later compared to adolescents with low levels of self-efficacy $(O R=.56$, 95\% $C I=.43-.73, P=.000)$. Further, adolescents were 
Table 3 Logistic regression analyses of adolescent smoking onset (discrete-time survival analyses)

\begin{tabular}{|c|c|c|c|c|}
\hline \multirow[t]{2}{*}{ Variable } & \multicolumn{2}{|c|}{ Adolescent-Mother } & \multicolumn{2}{|c|}{ Adolescent—Father } \\
\hline & OR & $95 \% \mathrm{CI}$ & OR & $95 \% \mathrm{CI}$ \\
\hline \multicolumn{5}{|l|}{ Step 1} \\
\hline Gender & .94 & $.60-1.47$ & .94 & $.60-1.46$ \\
\hline Age & .92 & $.76-1.12$ & .94 & $.78-1.14$ \\
\hline Education & .91 & $.72-1.16$ & .90 & $.70-1.14$ \\
\hline Ethnicity & 1.22 & $.98-1.52$ & 1.22 & $.98-1.52$ \\
\hline \multicolumn{5}{|l|}{ Step 2} \\
\hline Refusal self-efficacy $(\mathrm{T}-1)$ & $.57 * * *$ & $.44-.73$ & $.56 * * *$ & $.43-.73$ \\
\hline Quality of communication $(\mathrm{T}-1)$ & .81 & $.54-1.23$ & .91 & $.62-1.33$ \\
\hline Frequency of communication $(\mathrm{T}-1)$ & $1.65 * *$ & $1.14-2.39$ & $1.47 *$ & $1.05-2.06$ \\
\hline Parental smoking $(\mathrm{T}-1)$ & 1.05 & $.87-1.26$ & .93 & $.78-1.12$ \\
\hline Friends smoking $(\mathrm{T}-1)$ & $1.33 \dagger$ & $.96-1.83$ & $1.34^{\dagger}$ & $.98-1.84$ \\
\hline Best friend smoking $(\mathrm{T}-1)$ & 1.11 & $.97-1.28$ & $1.12^{\dagger}$ & $.98-1.28$ \\
\hline Sibling smoking $(\mathrm{T}-1)$ & $1.11 *$ & $1.01-1.22$ & $1.12 *$ & $1.02-1.23$ \\
\hline \multicolumn{5}{|l|}{ Step 3} \\
\hline Refusal self-efficacy $\times$ Quality of communication $(T-1)$ & .71 & $.45-1.11$ & .82 & $.52-1.30$ \\
\hline Refusal self-efficacy $\times$ Frequency of communication $(T-1)$ & .87 & $.58-1.31$ & .98 & $.67-1.41$ \\
\hline Refusal self-efficacy $\times$ Parental smoking $(\mathrm{T}-1)$ & .88 & $.72-1.09$ & .94 & $.77-1.15$ \\
\hline Refusal self-efficacy $\times$ Friends smoking $(T-1)$ & .91 & $.63-1.30$ & .84 & $.58-1.19$ \\
\hline Refusal self-efficacy $\times$ Best friend smoking $(T-1)$ & 1.09 & $.92-1.29$ & 1.09 & $.93-1.29$ \\
\hline Refusal self-efficacy $\times$ Sibling smoking $(T-1)$ & 1.01 & $.90-1.14$ & 1.02 & $.91-1.15$ \\
\hline
\end{tabular}

$\mathrm{T}-1=1$ year before the smoking behavior, OR Odds Ratio, 95\% CI 95\% Confidence Interval; Mother: $R^{2}=.013$ for Step $1, R^{2}=.139$ for Step $2 ; R^{2}=.151$ for Step 3 (Nagelkerke), Father: $R^{2}=.012$ for Step $1 ; R^{2}=.131$ for Step $2 ; R^{2}=.137$ for Step $3\left(\right.$ Nagelkerke). ${ }^{\dagger}=P<.10$, $* P<.05$, ** $P<.01$, *** $P<.001$

more likely to start smoking when the frequency of the father-child communication was higher at an earlier point in time $(O R=1.47,95 \% C I=1.05-2.06, P=.03)$, and adolescents were more likely to start smoking when older siblings smoked at the previous point in time $(O R=1.12$, 95\% $C I=1.02-1.23, P=.02)$. Adolescents were more likely to start smoking when they had more friends who smoked and when their best friend smoked (respectively $O R=1.34,95 \% \quad C I=.98-1.84, \quad P=.07 ; \quad O R=1.12$, $95 \% C I=.98-1.28, P=.08)$. In step 3, interaction effects between self-efficacy and frequency/quality of communication, smoking behavior of parents, sibling, friends, and best friend were added to the equation but no significant effects were found. ${ }^{1}$

\footnotetext{
${ }^{1}$ Interaction effects of quality of communication and frequency of communication with smoking behavior of the parent, smoking behavior of sibling, and smoking behavior of (best) friends were also tested (i.e., quality/frequency of communication * parental smoking, quality/frequency of communication * best friends smoking, quality/ frequency of communication $*$ sibling smoking). No moderation effects were found.
}

\section{Mother}

In step 1 and 2, similar results were found. Lower selfefficacy $(O R=.57,95 \% C I=.44-.73, P=.000)$, high frequency of maternal communication $(O R=1.65,95 \%$ $C I=1.14-2.39, P=.008)$, and sibling smoking $(O R=$ $1.11,95 \% C I=1.01-1.22, P=.04)$ were related to adolescent smoking onset 1 year later. Friends smoking $(O R=1.33,95 \% C I=.96-1.83, P=.08)$ was related to adolescent smoking onset 1 year later. No significant interaction effects were found in step 3 (Table 3).

In Fig. 2, the Kaplan-Meier survival curves (adjusted for censored episodes) are presented for self-efficacy, frequency of communication, and smoking of sibling. These variables were split up into low (0) and high (1) based on median split. The difference between low and high selfefficacy was significant (log-rank $=34.97, \quad P<0.001$; Fig. 2a). Adolescents who did not talk often about smoking-related issues with their parents were less likely to start smoking. The difference between low and high frequency of communication was also significant (mother: logrank $=12.93, P<0.05$; father: $\log$-rank $=12.15, P<$ 0.001) (Fig. 2c, d). In addition, a significant difference 

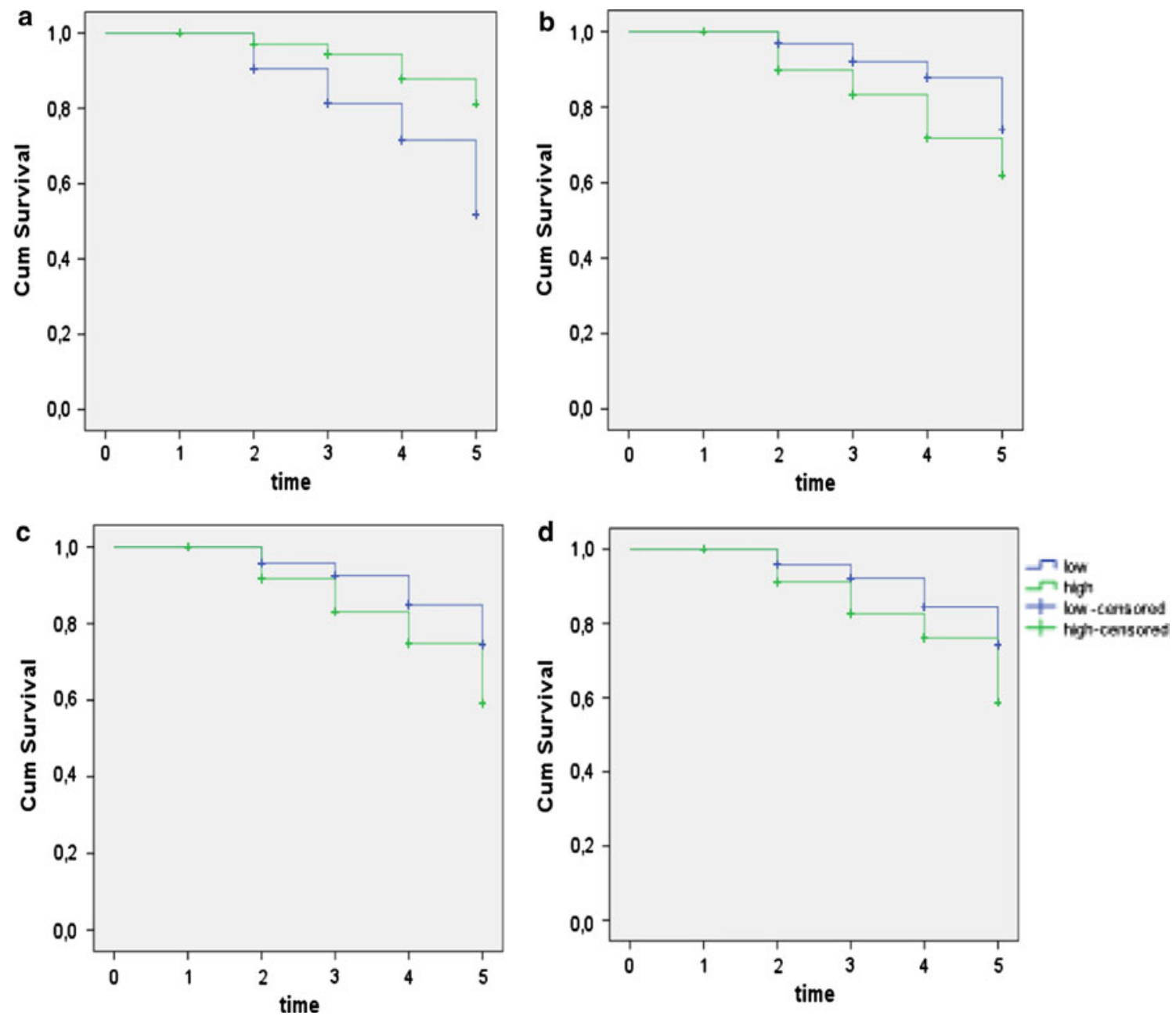

Fig. 2 Cumulative survival curves refusal self-efficacy a, smoking behavior sibling $\mathbf{b}$, and frequency of communication: mother $\mathbf{c}$ and father $\mathbf{d}$. Continuous variables were dichotomized based on median

between the low and high level of sibling smoking was found (log-rank $=17.24, P<0.001$ ), indicating that adolescents with smoking siblings are more likely to start smoking (Fig. 2b).

\section{Discussion}

The present study examined the timing of smoking onset during mid- or late adolescence and the role of the timevarying effects of refusal self-efficacy, parental smoking, sibling, friends and best friend's smoking, and smokingspecific parenting. Survival analyses were used to give insight into whether smoking onset occurred and when (e.g., Singer \& Willet, 1993). The majority of longitudinal studies predict smoking by looking at predictors at one point in time, partially ignoring the idea that the effects of certain predictors may change or fluctuate over time (Willet \& Singer, 1991). By looking at the particular time- split to low (below the median) and high (above the median). Each person who started smoking is showed as a downward step in the curve

related effects of different predictors, survival analyses are more accurate. Moreover, survival analyses minimize bias, because non-occurrence of smoking is taken into account (censoring). The present study looked at smoking onset in mid- or late adolescence.

Results of the life table approach provided important preliminary information about when smoking onset occurs during mid- or late adolescence by estimating survival and hazard rates. Findings revealed that $51 \%$ of all nonsmoking respondents at baseline did not start smoking within the study period. To be able to accurately compare these results with national data, also the early initiators need to be taken into account. At age 13-14 (baseline assessment), 153 respondents reported lifetime smoking and were excluded from the analyses. From the respondents that were included in the analyses, 120 respondents started smoking at some point during the study period. So, at the final assessment at age $17-19$, in total 273 respondents $(63.8 \%)$ had some experience with smoking, which is 
in line with national data on smoking in the Netherlands (Stivoro, 2009). Smoking initiation risks were quite similar throughout mid- and late adolescence (hazard ratio between .16 and .19).

Discrete-time survival analyses were used to assess the relationship between self-efficacy, smoking behavior of parents, sibling, friends' and best friend and smokingspecific communication, and adolescent smoking onset. An advantage of discrete-time survival analyses is that it takes into account the time-varying predictors, whose values fluctuate over time. We found that during mid- or late adolescence self-efficacy, sibling smoking, and frequency of communication assessed 1 year prior to onset are important predictors of smoking onset.

For self-efficacy, we found that adolescents with high levels of self-efficacy were less likely to start smoking in the following year, even after controlling for environmental smoking and smoking-specific parenting. This is in line with previous longitudinal research (Bidstrup et al., 2009; Chang et al., 2006; de Vries et al., 1995; Grogan et al., 2009; Lotrean et al., 2010). In a recent paper (Hiemstra et al., 2011), we found comparable effects of self-efficacy on adolescent smoking behavior over time. A decrease in self-efficacy over time is associated with smoking progression, even after controlling for parental, sibling, and friends' smoking behavior.

In addition, we also found that more frequent parental talking about smoking-related issues with their children was associated with an increased risk for children to start smoking. Specifically, frequency of communication about smoking related issues predicted smoking onset 1 year later. This finding might indicate that when adolescents start to experiment with more deviant behavior in general and drift towards deviant peers, parents might react to that by talking more often with their children. Previous crosssectional studies found similar results of higher frequency of communication (e.g., Ennett et al., 2001; Harakeh et al., 2005; Otten et al., 2007). However, contrary findings were also found (e.g., Chassin et al., 1998; Clark et al., 1999; Jackson \& Henriksen, 1997). Existing longitudinal studies found no association between frequency of communication and adolescent smoking onset (den Exter Blokland et al., 2006; Ennett et al., 2001). It could be that some of the inconsistent results are reflections of interactions between frequency of communication and quality of communication. For instance, it could be that in some studies parents engaged in both high levels of frequency of communication and high levels of quality of communication indeed causing preventive effects. Alternately, other parents could engage in high levels of frequency together with low levels of quality of communication actually increasing the risk for smoking. Another explanation could be that environmental smoking moderates the effects of frequency of communi- cation on adolescent smoking. No previous research has been conducted on the circumstances under which frequency of communication might have positive or aversive effects. Hence, more longitudinal studies should look into this to provide more insight into the circumstances in which frequency could be effective.

In contrast to other studies, no association was found between quality of communication and adolescent smoking onset (e.g., Chassin et al., 2005; de Leeuw et al., 2008). An explanation for not finding an association could be that parents only started talking about smoking matters, or changed their way of communicating, after their child had tried smoking (de Leeuw et al., 2010). ${ }^{2}$

Previous research found that smoking behavior of sibling, friends and parents is related to smoking onset (e.g., Avenevoli \& Merikangas, 2003; Bauman et al., 2001; Harakeh, et al., 2007), however these studies did not involve survival analyses. In the present study, we indeed found support for the relationship between sibling smoking behavior and adolescent smoking onset. An explanation for sibling smoking may be that younger siblings perceive older siblings as important role models, and they are likely to model their behavior (Harakeh et al., 2007). The effect of friends' smoking was marginally significant and no association between parental smoking and smoking onset was found. In this study, we looked at the first experience with smoking. Since the first smoking experience is with friends and the survival analyses concentrates at smoking onset at each point in time, this might have caused an absence of the effect of parental smoking. Moreover, samples with adolescents aged 13 or older it has been found that the influence of parental smoking is less important than that of friends' smoking on smoking onset (e.g., Gilman et al., 2009). Finally, in contrast to our expectations, no-interaction effects between self-efficacy and quality and frequency of communication, smoking behavior of parents, sibling, and friends were found. Refusal self-efficacy appears to be independent of the frequency and quality of parental communication and parents', friends' and sibling smoking.

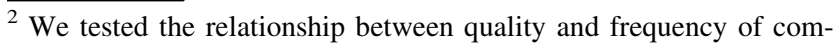
munication at current time point and adolescent smoking behavior at previous time point, while controlling for quality and frequency of communication at previous time points. We found that when a child started smoking, the following year frequency of communication would increase. We also found an inverse relationship between child smoking and quality of communication. Particularly, when a child started smoking, quality of communication would be lower the following year. Perhaps, the quality of communication decreases after children started smoking because parents no longer see the need of qualitative communication, while at the same time they may even be more likely to emphasize that smoking is a bad habit with serious health consequences, explaining the increasing frequency of communication levels. More research is necessary to test these and related hypotheses.
} 
Strengths, limitations, and implications

This study has several strengths. A longitudinal design was used, and by conducting survival analyses, the timing of smoking onset was taken into account as well as the nonoccurrence of an event (censoring). However, some limitations of this study should also be acknowledged. First, adolescents had to report about own smoking behavior and about smoking by their friends' and best friends. Although previous research has shown that self-report data about smoking (e.g., Dolcini et al., 2003) and adolescents' reports about friends' smoking habits (e.g., Harakeh et al., 2007) are generally reliable, multi-informant data would have been more complete. Second, by using survival analyses, adolescents with a history of smoking at the first assessment were excluded from the analyses. Early initiators differed from never smokers at the first assessment with respect to self-efficacy, environmental smoking, frequency of communication and quality of communication (Table 1). The mechanisms underlying smoking onset might differ for those who start early in adolescence as compared to those who start in mid- or late adolescence. It is therefore relevant to stress that conclusions of this study can only refer to adolescents who started smoking in mid- or late adolescence. Replications of this study should preferably include a younger cohort of children or adolescents to test whether the effects would remain significant in a younger group. Although we used data over a relatively long period of time, a prospective study that would cover the pre-adolescence period, adolescence, and young adulthood, would be very interesting. Third, it is possible that our findings are affected by selective drop-out, as attrition analyses showed that adolescents with lower education and more smoking friends were more likely to drop-out of the study. Lower education level (Hanson \& Chen, 2007) and more smoking friends (Hoffman et al., 2006; Kobus, 2003) are associated with higher levels of smoking, so caution is warranted when interpreting and generalizing our findings. Nevertheless, selective drop-out in our study was limited. Finally, generalizability to the larger population was limited since we only included intact families from Dutch origin (i.e., mother, father, and two children). Previous studies have shown higher smoking prevalence rates in adolescents from single-parent rather than two-parent families (Brown \& Rinelie, 2010; Lonczak et al., 2007).

In sum, the current findings showed that smoking initiation risks were quite similar throughout mid- and late adolescence and that refusal self-efficacy is an important longitudinal predictor of smoking onset and self-efficacy is independent of smoking-specific communication and smoking behavior of parents, sibling, and (best) friend(s). The results imply the importance of prevention programs that focus on teaching skills for resisting social pressure to use tobacco by helping adolescents to develop personal self-management and social skills (e.g., Life Skills Training: Botvin et al., 2003). Such interventions, with a recurrent character, could contribute to lower smoking onset rates in adolescents.

Acknowledgments We would like to thank Liesbeth Linssen for her statistical assistance. Supported by grant from the Dutch Cancer Society (2006-3464) and the Dutch Organization of Scientific Research (016-005-029; 400-05-051).

Conflict of interest The authors have no conflict of interest to declare.

Open Access This article is distributed under the terms of the Creative Commons Attribution Noncommercial License which permits any noncommercial use, distribution, and reproduction in any medium, provided the original author(s) and source are credited.

\section{References}

Allison, P. D. (1984). Event history analysis: Regression for longitudinal event data. Sage university paper series on quantitative applications in the social sciences (Serial No. 05-046). Beverly Hills, CA: Sage.

Allison, P. D. (1995). Survival analysis using the SAS system: A practical guide. SAS Institute Inc., Cary. USA: NC.

Avenevoli, S., \& Merikangas, K. R. (2003). Familial influences on adolescent smoking. Addiction, 98, 1-20. doi:10.1046/j.13600443.98.s1.2.x.

Ayo-Yusuf, A. A., van den Borne, B., Reddy, P. S., van Wyk, P. J., \& Severson, H. H. (2009). Longitudinal association of smokingrelated attitude to oral health with adolescents' smoking onset. Journal of Public Health Dentistry, 69, 29-33. doi:10.1111/ j.1752-7325.2008.00090.x.

Bandura, A. (1986). The social foundations of thought and action: A social cognitive theory. Prentice-Hall Series. Englewood Cliffs, NJ: Prentice-Hall.

Bauman, K. E., Carver, K., \& Gleiter, K. (2001). Trends in parent and friend influence during adolescence. The Case of Adolescent Cigarette Smoking. Addictive Behaviors, 26, 349-361. doi:10.1016/S0306-4603(00)00110-6.

Bidstrup, P. E., Frederiksen, K., Siersma, V., Mortensen, E. L., Ross, L., Vinther-Larsen, L., et al. (2009). Social-cognitive and school factors in initiation of smoking among adolescents: A prospective cohort study. Cancer Cancer Epidemiology, Biomarkers \& Prevention, 18, 384-392. doi:10.1158/1055-9965.EPI-08-0584.

Botvin, G. J., Griffin, K. W., Paul, E., \& Macaulay, A. P. (2003). Preventing tobacco and alcohol use among elementary school students through life skills training. Journal of Child \& Adolescent Substance Abuse, 12, 1-18. doi:10.1300/J029v12n04_01.

Bricker, J. B., Peterson, A. V., Sarason, I. G., Anderson, M. R., \& Rajan, K. B. (2007). Changes in the influence of parents' and close friends' smoking on adolescent smoking transitions. Addictive Behaviors, 32, 740-757. doi:10.1016/j.addbeh.2006. 06.020.

Brown, S. L., \& Rinelie, L. N. (2010). Family Structure, Family Processes, and Adolescent Smoking and Drinking. Journal of Research on Adolescence, 20, 259-273. doi:10.1111/j.15327795.2010.00636.x.

Chang, F. C., Lee, C. M., Lai, H. R., Chiang, J. T., Lee, P. H., \& Chen, W. J. (2006). Social influences and self-efficacy as 
predictors of youth smoking initiation and cessation: A 3-year longitudinal study of vocational high school students in Taiwan. Addiction, 101, 1645-1655. doi:10.1111/j.1360-0443.2006. 01607.x.

Chassin, L., Clark, C. P., Pitts, S. C., \& Sherman, S. J. (2000). The natural history of cigarette smoking from adolescence to adulthood in a midwestern community sample: Multiple trajectories and their psychosocial correlates. Health Psychology, 19, 223-231. doi:10.1037/0278-6133.19.3.223.

Chassin, L., Presson, C. C., Rose, J., Sherman, S. J., Davis, M. J., \& Gonzalez, J. L. (2005). Parenting style and smoking-specific parenting practices as predictors of adolescent smoking onset. Journal of Pediatric Psychology, 30, 333-344. doi:10.1093/ jpepsy/jsi028.

Chassin, L., Presson, C. C., Todd, M., Rose, J. S., \& Sherman, S. J. (1998). Maternal socialization of adolescent smoking: The intergenerational transmission of parenting and smoking. Developmental Psychology, 34, 1189-1201. doi:10.1037/0012-1649. 34.6.1189.

Clark, P. I., Scarisbrick-Hauser, A., Gautam, S. P., \& Wirk, S. J. (1999). Anti-tobacco socialization in homes of African-American and white parents, and smoking and nonsmoking parents. Journal of Adolescent Health, 24, 329-339. doi:10.1016/S1054139X(98)00117-7.

Conrad, K. M., Flay, B. R., \& Hill, D. (1992). Why children start smoking cigarettes: Predictors of onset. British Journal of Addiction, 87, 1711-1724. doi:10.1111/j.1360-0443.1992.tb02 684.x.

de Leeuw, R. N. H., Scholte, R. H. J., Harakeh, Z., van Leeuwe, J. F. J., \& Engels, R. C. M. E. (2008). Parental smoking-specific communication, adolescents' smoking behavior and friendship selection. Journal of Youth and Adolescence, 37, 1229-1241. doi:10.1007/s10964-008-9273-z.

de Leeuw, R., Scholte, R., Vermulst, A., \& Engels, R., (2010). The relation between smoking-specific parenting and smoking trajectories of adolescents: How are changes in parenting related to changes in smoking? Psychology \& Health, 1-23, doi: 10.1080/08870440903477204.

de Vries, H., Backbier, E., Kok, G., \& Dijkstra, M. (1995). The impact of social influences in the context of attitude, selfefficacy, intention, and previous behavior as predictors of smoking onset. Journal of Applied Social Psychology, 25, 237-257. doi:10.1111/j.1559-1816.1995.tb01593.x.

de Vries, H., Dijkstra, M., \& Kuhlman, P. (1988). Self-efficacy: The third factor besides attitude and subjective norm as a predictor of behavioral intentions. Health Education Research, 3, 273-282. doi:10.1093/her/3.3.273.

de Vries, H., Engels, R. C. M. E., Kremers, S., Wetzels, J., \& Mudde, A. (2003). Parents' and friends' smoking status as predictors of smoking onset: findings from six European countries. Health Education Research, 18, 627-636. doi:10.1093/her/cyg032.

den Exter Blokland, E. A. W., Hale, W. W., I. I. I., Meeus, W., \& Engels, R. C. M. E. (2006). Parental anti-smoking socialization: associations between parental anti-smoking socialization practices and early adolescent smoking initiation. European Addiction Research, 12, 25-32. doi:10.1159/000088580.

Dolcini, M. M., Adler, N. E., Lee, P., \& Bauman, K. E. (2003). An assessment of the validity of adolescent self-reported smoking using three biological indicators. Nicotine Tobacco Research, 5 , 473-483. doi:10.1080/1462220031000118586.

Engels, R. C. M. E., Knibbe, R. A., \& Drop, M. J. (1999). Predictability of smoking in adolescence: Between optimism and pessimism. Addiction, 94, 115-124. doi:10.1046/j.1360-0443. 1999.9411158.x.

Engels, R. C. M. E., Knibbe, R. A., Drop, M. J., \& De Haan, Y. T. (1997). Homogeneity of cigarette smoking within peer groups:
Influence or selection? Health Education \& Behavior, 24, $801-811$

Engels, R. C. M. E., \& Willemsen, M. (2004). Communication about smoking in Dutch families: Associations between anti-smoking socialization and adolescent smoking-related cognitions. Health Education Research, 19, 227-238. doi:10.1093/her/cyg042.

Ennett, S. T., Bauman, K. E., Foshee, V. A., Pemberton, M., \& Hicks, K. A. (2001). Parent-child communication about adolescent tobacco and alcohol use: what do parents say and does it affect youth behavior? Journal of Marriage and the Family, 63, 48-62. doi:10.1111/j.1741-3737.2001.00048.x.

Gilman, S. E., Rende, R., Boergers, J., Abrams, D. B., Buka, S. L., Clark, M. A., et al. (2009). Parental smoking and adolescent smoking initiation: an intergenerational perspective on tobacco control. Pediatrics, 123, e274-e281. doi:10.1542/peds.20082251.

Grogan, S., Conner, M., Fry, G., Gough, B., \& Higgins, A. (2009). Gender differences in smoking: A longitudinal study of beliefs predicting smoking in 11-15 year olds. Psychology \& Health, 24, 301-316. doi:10.1080/08870440701746586.

Hanson, M. D., \& Chen, E. (2007). Socioeconomic status and health behaviors in adolescence: A review of the literature. Journal of Behavioral Medicine, 30, 263-285. doi:10.1007/s10865-0079098-3.

Harakeh, Z., Engels, R. C. M. E., Vermulst, A. A., de Vries, H., \& Scholte, R. H. J. (2007). The influence of best friends and siblings on adolescent smoking: A longitudinal study. Psychology and Health, 22, 269-289. doi:10.1080/14768320600843218.

Harakeh, Z., Scholte, R. H. J., de Vries, H., \& Engels, R. C. M. E. (2005). Parental rules and communication: Their association with adolescent smoking. Addiction, 100, 862-870. doi:10.1111/ j.1360-0443.2005.01067.x.

Harakeh, Z., Scholte, R. H. J., Vermulst, A. A., de Vries, H., \& Engels, R. C. M. E. (2004). Parental factors and adolescents' smoking behavior: An extension of the theory of planned behavior. Preventive Medicine, 39, 951-961. doi:10.1016/ j.ypmed.2004.03.036w.

Hiemstra, M., Otten, R., de Leeuw, R. N. H., van Schayck, O. C. P., \& Engels, R. C. M. E. (2011). The changing role of self-efficacy in adolescent smoking initiation: A four-year longitudinal study. Journal of Adolescent Health, 48(6), 597-603. doi:10.1016/ j.jadohealth.2010.09.011.

Hoffman, B. R., Sussman, S., Unger, J. B., \& Valente, T. W. (2006). Peer influences on adolescent cigarette smoking: A theoretical review of the literature. Substance Use and Misuse, 41, 103-155. doi:10.1080/10826080500368892.

Huver, R. M. E., Engels, R. C. M. E., \& de Vries, H. (2006). Are antismoking parenting practices related to adolescent smoking cognitions and behavior? Health Education Research, 21, 66-77. doi:10.1093/her/cyh045.

Jackson, C., \& Dickinson, D. (2003). Can parents who smoke socialize their children against smoking? Results from the smoke-free kids intervention trial. Tobacco Control, 12, 52-59. doi:10.1136/tc.12.1.52.

Jackson, C., \& Henriksen, L. (1997). Do as I say: Parent smoking, anti smoking socialization and smoking onset among children. Addictive Behaviors, 22, 107-114. doi:10.1016/0306-4603 (95)00108-5.

Kaplan, E. L., \& Meier, P. (1958). Nonparametric estimation from incomplete observations. Journal of the American Statistical Association, 53(282), 457-481. Retrieved from: http://www. jstor.org/stable/2281868.

Kobus, K. (2003). Peers and adolescent smoking. Addiction, 98, 37-55. doi:10.1046/j.1360-0443.98.s1.4.x.

Kremers, S. P., Mudde, A. N., \& de Vries, H. (2001). "Kicking the initiation": Do adolescent ex-smokers differ from other groups 
within the initiation continuum? Preventive Medicine, 33, 392-401. doi:10.1006/pmed.2001.0904.

Lonczak, H. S., Fernandez, A., Austin, L., Marlatt, G. A., \& Donavan, D. M. (2007). Family structure and substance use among American Indian youth: A preliminary study. Families, Systems \& Health, 25, 10-22. doi:10.1037/1091-7527.25.1.10.

Lotrean, L. M., Dijk, F., Mesters, I., Ionut, C., \& de Vries, H. (2010). Evaluation of a peer-led smoking prevention programme for Romanian adolescents. Health Education Research. Jul 2. doi:10.1093/her/cyq034.

Mayhew, K. P., Flay, B. R., \& Mott, J. A. (2000). Review: Stages in the development of adolescent smoking. Drug and Alcohol Dependence, 59, S61-S81.

Morbidity \& Mortality Week Report (MMWR) (2010) Youth risk behavior surveillance-United States, 2009. CDC June 2010 vol 59 (No SS5) page 1-142.

Muthen, B., \& Masyn, K. (2005). Discrete-time survival mixture analysis. Journal of Educational and Behavioral statistics. 31(1), 27-58. Retrieved from: http://www.jstor.org/stable/3701319.

National Centre for Social Research (2010). Smoking, drinking and drug use among young people in England in 2009. NHS Information centre for health and social care.

Otten, R., Harakeh, Z., Vermulst, A. A., van den Eijnden, R. J. J. M., \& Engels, R. C. M. E. (2007). Frequency and quality of parental communication as antecedents of adolescent smoking cognitions and smoking onset. Psychology of Addictive Behaviors, 21, 1-12. doi:10.1037/0893-164X.21.1.1.

Otten, R., Wanner, B., Vitaro, F., \& Engels, R. C. M. E. (2009). Disruptiveness, peer experiences and adolescent smoking: a long-term longitudinal approach. Addiction, 104, 641-650. doi:10.1111/j.1360-0443.2008.02480.x.

Petraitis, J., Flay, B. R., \& Miller, T. Q. (1995). Reviewing theories of adolescent substance use organizing pieces in the puzzle. Psychological Bulletin, 117, 67-86.

Singer, J.D., \& Willet, J.B. (1993). It's about time: using discretetime survival analysis to study duration and the timing of events. Journal of Educational and Behavioral Statistics, 18(2), 155-195. Retrieved from: http://www.jstor.org/stable/1165085.

Singer, J. D., \& Willet, J. B. (2003). Applied longitudinal data analysis: Modeling change and event occurrence. Oxford: Oxford University Press.

Stivoro (2009) Roken, de harde feiten: Jeugd 2009. [Smoking, the hard facts: Youth 2009]. The Hague, The Netherlands: Stivoro 2009. Retrieved from: http://www.stivoro.nl/Upload/artikel/ Cijfers/Factsheet\%20jeugd\%202009.pdf.

Systema, S., Micciolo, R., \& Tansella, M. (1996). Service utilization by schizophrenic patients in. Groningen and South-Verona: an event-history analysis Psychological Medicine, 26, 111-122.

Willet, J.B., \& Singer, J.D. (1991). From whether to when: new methods for studying student dropout and teacher attrition. Review of Educational Research, 61, 407-450. Retrieved from: http://www.jstor.org/stable/1170572.

Willet, J. B., \& Singer, J. D. (1993). Investigating onset, cessation, relapse, and recovery: Why you should, and how you can, use discrete-time survival analysis to examine event occurrence. Journal of Consulting and Clinical Psychology, 61, 952-965. doi:10.1037/0022-006X.61.6.952. 